\title{
Legislação da saúde prisional em análise
}

\author{
Legislación de la salud prisional en análisis
}

Prison health legislation under review

\author{
Samanta Costa Calcagno ${ }^{1}$ \\ João Alberto da Silva ${ }^{2}$ \\ Julio Cesar Bresolin Marinho ${ }^{3}$
}

\begin{abstract}
Resumo
A superlotação das instituições prisionais representa um agravo para a saúde das pessoas presas. Para o gênero feminino essa situação é ainda pior, visto que a carência de presídios para abrigar mulheres acaba prejudicando sua saúde. Dessa forma, o objetivo deste trabalho visa investigar as políticas públicas voltadas à saúde de pessoas presas, com o enfoque especial nas mulheres. A pesquisa configura-se como documental, pois a análise documental pode ser adotada quando a fonte de investigação carrega em si elementos fundamentais para a pesquisa. Como corpus de análise elencamos: a Constituição Federal (1988); A Lei no 8.080, de 19 de setembro de 1990 (Lei orgânica de saúde); Lei de Execução Penal no 7.210, de 1984; Portaria Internacional nº 1.777, de 9 de setembro de 2013 Plano Nacional De Saúde No Sistema Penitenciário (PNSSP); Portaria $n^{\circ} 277$, de 27 de janeiro de 2017 Política Nacional de Atenção Integral à Saúde das Pessoas Privadas de Liberdade no Sistema Prisional (PNAISP); Portaria Interministral no 210, de 16 de janeiro de 2014 Política Nacional de Atenção às Mulheres em Situação de Privação de Liberdade e Egressas do Sistema Prisional (PNAMPE). Foi possível verificar que há grande amparo legislativo referente á saúde da população prisional, sobretudo referente às pessoas do gênero feminino. Contudo, impasses como a falta de recursos humanos, o grande contingente populacional, a arquitetura prisional inadequada para abrigar as mulheres, são alguns entraves que interferem na efetividade de todas essas leis.
\end{abstract}

Palavras-Chave: Presídios; Saúde; Gênero feminino, Legislação.

\section{Resumen}

La superpoblación en las instituciones penitenciarias representa un agravio para la salud de las personas detenidas. Para el género femenino esta situación es aún peor, ya que la carencia de presidios para albergar a las mujeres acaba perjudicando su salud. De esta forma, el objetivo de este trabajo busca investigar las políticas públicas orientadas a la salud de personas presas, con el enfoque especial en las mujeres. La investigación se configura como documental, pues el análisis documental puede ser adoptado cuando la fuente de investigación lleva en sí elementos fundamentales para la investigación. Como corpus de análisis se tiene: la Constitución Federal (1988); La Ley n ${ }^{\circ}$ 8.080, de 19 de septiembre de 1990 (Ley orgánica de salud); Ley de Ejecución Penal $\mathrm{n}^{\mathrm{o}}$ 7.210, de 1984; Portaria Internacional $\mathrm{n}^{\circ}$ 1.777, de 9 de septiembre de 2013 Plan Nacional de Salud en el Sistema Penitenciario (PNSSP); En el caso de las personas privadas de libertad en el sistema penitenciario (PNAISP), la normativa nacional de atención integral a la salud de las personas privadas de libertad en el sistema penitenciario (PNAISP), de 27 de enero de 2017; En el caso de las mujeres en situación de privación de libertad y egresadas del sistema penitenciario (PNAMPE), la política nacional de atención a las mujeres en situación de

\footnotetext{
${ }^{1}$ Mestranda em Educação em Ciências pelo Programa de Pós-Graduação em Educação em Ciências: Química da Vida e Saúde da Universidade Federal do Rio Grande- FURG, Rio Grande, RS, Brasil, samantacalcagno@hotmail.com

${ }^{2}$ Doutor em Educação e Professor da Universidade Federal do Rio Grande- FURG Rio Grande- RS, Brasil, joaosilva@furg.com

3 Julio Cesar Bresolin Marinho Doutor em Educação em Ciências e Professor da Universidade Federal do Pampa- UNIPAMPA Campus São Gabriel, RS, Brasil juliomarinho@unipampa.edu.br
} 
privación de libertad y decretadas del sistema penitenciario (PNAMPE). Fue posible verificar que hay gran amparo legislativo referente a la salud de la población prisional, sobre todo referente a las personas del género femenino. Sin embargo, impases como la falta de recursos humanos, el gran contingente poblacional, la arquitectura inadecuada de los recintos penitenciarios para albergar a las mujeres, son algunos obstáculos que interfieren en la efectividad de todas esas leyes.

Palabras Clave: Presídios; Salud; Género femenino, Legislación.

\begin{abstract}
The overcrowding of prisons represents an injury to the health of prisoners. For the female gender this situation is even worse, since the lack of prisons to shelter women ends up harming their health. Thus, the objective of this study is to investigate public policies aimed at the health of prisoners with a special focus on women. The research is set up as documentary. That can be adopte when the research source carries in itself fundamental elements for the research. As corpus of analysis we mention: the Brazilian Federal Constitution (1988); Law $n^{\circ}$ 8.080, september 19, 1990 (Organic Health Law); Law of Criminal Execution $\mathrm{n}^{\circ}$ 7.210, 1984; International Ordinance $n^{\circ}$ 1.777, september 9, 2013 National Health Plan in the Penitentiary System; Ordinance $n^{\circ} 277$, january 27, 2017 National Policy for Integral Attention to the Health of Persons Deprived of Liberty in the Prison System; Interministerial Ordinance $\mathrm{n}^{\circ}$ 210, dated january 16, 2014 National Policy on Attention to Women in Situation of Deprivation of Liberty and Exit from the Prison System. It was possible to verify that there is great legislative protection regarding the health of the prison population, especially referring to the female people. However, impasses such as the lack of human resources, the large contingent population, inadequate prison architecture to shelter women, are some of the obstacles that interfere with the effectiveness of all these laws.
\end{abstract}

Keywords: Prisons; Health; Feminine, Legislation.

\title{
1. Introdução
}

Com a criação e implementação do Sistema Único de Saúde (SUS) o Brasil, se tornou referencia internacional no âmbito da saúde pública com um sistema mais igualitário, que prevê o acesso aos serviços de saúde como direito universal para todas as pessoas, ficando a cargo do Estado a responsabilidade pela proteção, promoção e cuidado da saúde da população, em todos os espaços.

A compreensão sobre saúde envolve subjetividade, valores tanto individuais com socioculturais. Dessa forma, o desenvolvimento, o cuidado e a promoção da saúde devem ser efetivados também dentro das casas prisionais, pois concebemos que as pessoas reclusas em presídios também devem ter assegurado à eficácia das ações de promoção, prevenção e atenção integral à saúde.

De acordo com o artigo $3^{\circ}$ da Lei de Execução Penal (LEP), todas as pessoas que estão presas devem ter acesso à saúde integral que é provida pelo Estado e previsto na a Constituição Federal de 1988. Os atendimentos refrentes a saúde podem ser desenvolvidos por médicos, farmacêuticos e dentistas.

Com relação à distribuição de profissionais da área da saúde que atuam nas unidades prisionais femininas e mistas do Rio Grande do Sul (RS), o Infopen Mulheres (2018) divulgou os seguintes números: 69 profissionais da área da saúde, divididos nas seguintes 
especificidade - 5 enfermeiros; 36 auxiliares técnicos de enfermagem, 6 dentistas; 2 técnico/auxiliar odontológico; 7 médicos clínicos geral; zero médicos ginecologista; 12 médicos psiquiatras; um médico de outras especificidades.

Segundo dados coletados em junho de 2016 pelo Departamento Penitenciário Nacional (DEPEN) e divulgados pelo INFOPEN Mulheres (2018); o Rio Grande do Sul possuía naquele momento 1.965 mulheres presas, dessas 1.577 estavam em unidades prisionais com módulo de saúde, ${ }^{4}$ outras 388 mulheres em unidades prisionais sem módulo de saúde. Ainda que o contingente do gênero feminino em unidades prisionais com módulos de saúde fosse expressivo, há carência de unidades prisionais que atendam o previsto pela legislação.

A legitimação do direito a saúde sem qualquer discriminação havendo pleno gozo desse direito perpassa as ações de saúde. Essa formulação é política e também organizacional com base em princípios éticos que promovam saúde com qualidade e de forma efetiva, sem que possa ser confundida como algo com valor de mercado, mas sim como direito humano para todas as pessoas, inclusive as que estão sobre tutela do Estado.

Os princípios que compõe a Lei ${ }^{\circ} 8.080$, de 19 de setembro de 1990 asseguram que a saúde seja executada de forma ética e humanizada são: a universalidade (garantia de atenção à saúde a todo e qualquer cidadão); a equidade (direito ao atendimento adequado às necessidades de cada indivíduo e coletividade) e a integralidade (a pessoa é um todo indivisível inserido numa comunidade) (Brasil, 1990). Desta forma, a saúde é um direito fundamental assegurado pela Constituição Federal assegurado por uma gama robusta de leis, e por isso, não pode ser confundido como um privilégio ou como uma mercadoria.

O objetivo deste trabalho visa investigar as políticas públicas voltadas à saúde de pessoas presas, com o enfoque especial nas mulheres Iremos discutir a relevância dessas legislações e dessas políticas, buscando compreender e a representatividade que elas trouxeram para a garantir o direito à saúde das mulheres presas.

\section{Metodologia}

Trata-se de uma pesquisa de cunho qualitativo e configura-se como uma análise documental que é uma técnica relevante, pois revela aspectos novos de um problema ou temática. A análise documental representa uma fonte fidedigna de informações, segundo Ludke e André (1986, p. 39) "não são apenas uma fonte de informações contextualizada, mas surge num determinado contexto e fornecem informações sobre esse mesmo contexto". Dessa

\footnotetext{
${ }^{4}$ São unidades de saúde dentro da instituição prisional.
} 
forma, a análise documental pode ser adotada quando a fonte de investigação carrega em si elementos fundamentais para a pesquisa, como no caso da investigação da legislação referente à saúde.

Nosso corpus de pesquisa reside no escopo da legislação federal brasileira referente à saúde pública e saúde prisional, visto que nosso objetivo reside em investigar as políticas públicas voltadas à saúde de pessoas presas, com o enfoque especial nas mulheres.

O contato com as fontes teve início no primeiro semestre de 2017 e se estendeu até outubro de 2018. Foi analisada a Constituição Federal de 1988, basicamente sua seção II referente ao que prevê sobre saúde; a Lei $\mathrm{n}^{\circ}$ 8.080, de 19 de setembro de 1990 que dispõe sobre as condições para a promoção, proteção e recuperação da saúde, a organização e o funcionamento dos serviços correspondentes e dá outras providências; Lei de Execução Penal $\mathrm{n}^{\circ}$ 7.210, de 1984 (LEP); Portaria Internacional $n^{\circ}$ 1.777, de 9 de setembro de 2013 Plano Nacional De Saúde No Sistema Penitenciário (PNSSP); a Portaria n ${ }^{\circ} 277$, de 27 de janeiro de 2017 Política Nacional de Atenção Integral à Saúde das Pessoas Privadas de Liberdade no Sistema Prisional (PNAISP); Portaria Interministral n 210, de 16 de janeiro de 2014 Política Nacional de Atenção às Mulheres em Situação de Privação de Liberdade e Egressas do Sistema Prisional (PNAMPE).

Como forma de contato com as leis, acessamos os endereços eletrônicos do Ministério da Saúde, do Conselho Nacional de Secretaria de Saúde (CONASS); da Câmara dos deputados. Nesses endereços foram encontradas as leis que analisamos. Todas elas foram lidas e analisadas em sua integra tendo os pontos referentes à saúde prisional feminina recebendo maior atenção.

\section{Políticas de saúde do SUS e o sistema prisional}

Com o intuito de analisar a legislação brasileira referente ao amparo à saúde, buscaremos nos apoiar nela como forma de respaldo, e caminho para a compreensão do que prevê as políticas públicas que objetivam zelar pela saúde no contexto prisional.

De acordo com o que prevê a Constituição Federal de 1988, ao que se refere ao direito à saúde:

Art. 196. A saúde é direito de todos e dever do Estado, garantido mediante políticas sociais e econômicas que visem à redução do risco de doença e de outros agravos e ao acesso universal e igualitário às ações e serviços para sua promoção, proteção e recuperação. Art. 197. São de relevância pública as ações e serviços de saúde, cabendo ao Poder Público dispor, nos termos da lei, sobre sua regulamentação, fiscalização e controle, devendo sua execução ser feita diretamente ou através de terceiros e, também, por pessoa física ou jurídica de direito privado (BRASIL, 1988, p. 118). 
A Constituição prevê o direito ao acesso à saúde para todos os cidadãos brasileiros. Logo a população prisional, assim como toda a população, tem direito de acesso ao Sistema Único de Saúde (SUS), em todos os níveis de complexidade.

A Lei $\mathrm{N}^{\circ}$ 8.080, de 19 de setembro de 1990, dispõe sobre as condições para a promoção, proteção e recuperação da saúde, a organização e o funcionamento dos serviços correspondentes à saúde mental. Além disso, ela regula as ações e serviços de saúde, executados de forma isolada ou em conjunto, em todo o território nacional.

O Estado deve garantir à saúde em amplas instâncias, formulando e executando políticas que sustentem e deem condições para a redução de riscos e agravos das doenças. Essas condições devem assegurar o acesso universal e igualitário dentro dos preceitos do SUS, que visa atuar em rede (integração dos serviços interfederativos), regionalização (região de saúde) e hierarquização (níveis de complexidade dos serviços). Estes são os pilares que sustentam o modelo de atenção à saúde, conforme dispõem o artigo 198 da Constituição Federal.

Sendo a saúde um dos direitos fundamentais, deve haver o amparo à saúde dentro das casas prisionais, para que com isso, a população que lá se encontra tenha seu direito resguardado pelo Estado. Se a lei for aplicada e fiscalizada de forma satisfatória não haverá brechas para que a saúde no sistema prisional não seja executado de forma satisfatória, tal como previsto pela legislação. Dessa forma, o atendimento de saúde para as detentas poderá estar de acordo com o princípio da dignidade da pessoa humana. Essas ações devem ser realizadas, de forma independente ao juízo de valor referente ao merecimento social ou pessoal. A saúde é um direito da vida, por isso, não há necessidade de se atribuir um merecimento.

Contudo, essa não é a realidade de grande parte (se não) da maioria das pessoas que estão em situação prisional, uma vez que as condições estruturais tanto de resursos humanos quanto referente a materiais nas cadeias são deficientes e insuficientes. Isso implica sobretudo para a higiene e para a saúde da população prisional. Nesse contexto, as mulheres são as que mais sofrem com essa precariedade, pois os serviços penitenciários em sua maioria não são planejados e nem construídos para o público do gênero feminino. Dessa forma, existe um desrespeito até mesmo com relação às necessidades ginecológicas desse público em especial.

Os serviços de atenção e cuidado a saúde devem agir para a promoção, proteção e recuperação. De acordo com o Art. $3^{\circ}$ da Lei orgânica da saúde: 
Os níveis de saúde expressam a organização social e econômica do País, tendo a saúde como determinantes e condicionantes, entre outros, a alimentação, a moradia, o saneamento básico, o meio ambiente, o trabalho, a renda, a educação, a atividade física, o transporte, o lazer e o acesso aos bens e serviços essenciais (BRASIL, 1990, p. 1).

Essas disposições harmonizam-se as práticas que se destinam a garantia de saúde das pessoas e também dos coletivos, proporcionando condições de bem-estar físico, mental e social. É de responsabilidade do poder público em esferas federal, estadual e municipal controlar a qualidade dos insumos, podendo ter participação da iniciativa privada. Desta forma, a organização dos serviços de saúde será regionalizada e hierarquizada em níveis de complexidade crescente para atender as demandas da população prisional demandas da população dentro das suas necessidades.

De acordo com a Lei $N^{\circ} 8.080$, de 19 de setembro de 1990, o SUS tem como sustentação um tripé que é formado por três princípios: a universalidade, que garante o acesso a todos os indivíduos aos níveis de saúde (baixa, média, e alta complexidade); complementarmente a integralidade surge como um dos princípios mais elementares, pois é por meio dela que a assistência se dará por meio de um conjunto articulado e contínuo, prevendo serviços preventivos e curativos buscando atender as especificidades individuais assim como ações coletivas e a equidade que objetiva diminuir as desigualdades, e prevê que não ocorram preconceitos ou privilégios nos atendimento, tratando de forma desigual os desiguais.

Com o intuito de construir uma base para o entendimento com relação ao direito ao acesso à saúde da população prisional, torna-se necessário fazer uma abordagem ampla sobre as leis nacionais, no sentido de trazer para a discussão outros tópicos fundamentais à compreensão da incoerência da realidade prisional no que tange ao quesito saúde.

A população prisional tem assegurado legalmente o acesso à saúde e isso está definido pela Lei de Execução Penal nº 7.210, de 1984; pela Constituição Federal de 1988; pela Lei n. ${ }^{\circ}$ 8.080, de 1990 (que regulamenta o Sistema Único de Saúde); pela Portaria Internacional no 1.777, de 9 de setembro de 2013 (que institui o Plano Nacional de Saúde no Sistema Penitenciário); e a portaria $\mathrm{n}^{\circ} 277$, de 27 de janeiro de 2017 sobre à Política Nacional de Atenção Integral à Saúde das Pessoas Privadas de Liberdade no Sistema Prisional (PNAISP) no âmbito do Sistema Único de Saúde (SUS).

A Lei das Execuções Penais (LEP), em seu primeiro artigo, traz como seu objetivo efetivar as disposições de sentença ou decisão criminal e proporcionar condições para a harmônica integração social do condenado e do internado. 
[...] a Lei n. ${ }^{\circ}$ 7.210, de 11.7.1984, estabeleceu que, no prazo de 6 (seis) meses após a sua publicação, deveriam as unidades federativas, em convênio como Ministério da Justiça, "projetar a adaptação, construção e equipamento de estabelecimentos e serviços penais previstos nesta Lei” (art. 203, § 1. ${ }^{\circ}$ ). Também, no mesmo prazo, deveria "ser providenciada a aquisição ou desapropriação de prédios para instalação de casas de albergados" (art. 203, § $2^{\circ}$ ) (DOTTI, 2003, p. 78).

Criada em 11 de julho de 1984, a LEP está prestes a completar 34 anos de sua criação, e até hoje o objetivo da lei não é executado de forma satisfatória. A lei prevê adotar o sistema de progressão de pena, o que vemos atualmente é um aumento considerável e bruto no encarceramento. Com isso, o contexto prisional ainda sofre com a falta de condições capazes de integrar os apenados ao meio social. Um dos desafios da LEP é organizar os regimes e os estabelecimentos prisionais.

Ainda sobre a referida Lei, ao que se refere à saúde em sua seção III, que trata especificamente da assistência à saúde, compreenderá atendimento médico, farmacêutico e odontológico. Em caso do estabelecimento não ter aparelhamento médico necessário, a assistência deverá ser prestada em outro local, sob autorização da direção do estabelecimento.

A LEP ainda prevê assegurar acompanhamento médico à mulher (principalmente no pré-natal e no pós-parto) de modo que os cuidados sejam extensivos para o bebê. Como forma de complemento a Lei $\mathrm{n}^{\mathrm{o}} 7.210$ de 11 de julho de 1984, surge a Lei $\mathrm{n}^{\circ} 11.942$, de 28 de maio de 2009 que deu nova redação aos artigos 14, 83 e 89 da LEP. A lei assegura às mães presas, e aos recém-nascidos, condições mínimas de assistência. As mudanças proporcionadas foram de grande significado. De acordo com essas mudanças:

(ii) proporcionou estabelecimentos prisionais com espaços para berçários para abarcar os filhos das presidiárias no período da amamentação até os 06 (seis) meses de idade; (iii) assegurou a existência de seção para gestante e parturiente, bem como creches para crianças de 06 (seis) meses e menores de 07 (sete) anos para assistir a criança desamparada, cuja mãe estiver cumprindo pena privativa de liberdade e (iv) assegurou que a seção e a creche serão acompanhadas por pessoal qualificado, atendendo às normas educacionais (BRASIL, 2009, p. 1).

Todavia, atualmente, nem todas essas ações previstas em leis são postas em prática, e o que vemos são muitas mulheres e seus filhos tendo seus direitos negligenciados, e violados pelo próprio Estado que deveria prestar a seguridade e proteção a essas pessoas.

O Plano Nacional de Saúde no Sistema Prisional - PNSSP (2004) prevê a prática, e definição de ações de saúde dentro do âmbito prisional. Essas ações devem estar de acordo com os princípios e diretrizes do SUS, tornando viável a atenção integral à saúde da população prisional com cobertura em todo o território nacional. 
De acordo com estimativas do PNSSP (2004), devido aos fatores de risco que a população prisional está exposta, o percentual do adoecimento dessas pessoas é maior nos casos de algumas doenças. Desta forma, para elucidar de maneira mais explicativa, elaboramos com base nos dados retirados da PNSSP (2004), um quadro que descreve as patologias mais comuns na prisão.

\begin{tabular}{|l|}
\hline \multicolumn{1}{|c|}{ Patologias } \\
\hline Tuberculose \\
\hline Hipertensão e diabetes (Diabetes mellitus) \\
\hline Dermatologia sanitária - hanseníase; dermatoses \\
\hline DST/ HIV/AIDS \\
\hline Saúde da Mulher \\
\hline Diarreias infecciosas \\
\hline Hepatites \\
\hline Pneumonias \\
\hline Saúde bucal \\
\hline Saúde mental (Transtornos mentais) \\
\hline Traumas \\
\hline
\end{tabular}

Quadro 1: Quadro-síntese das patologias usuais da população encarcerada Fonte: Plano Nacional de Saúde no Sistema Penitenciário-PNSSP (BRASIL, 2004).

Essas patologias ocorrem em um percentual significativo na população encarcerada, por isso evidenciamos a necessidade de estudos, ações preventivas e promotoras da saúde nos presídios.

Conforme previsto na PNSSP (2003), as condutas de saúde a serem desenvolvidas devem estar em concordância com as patologias mais verificadas no ambiente prisional, assim como para as especificidades populacionais. Para que as especificidades sejam atendidas devem ser obedecidos protocolos mínimos de saúde, e o desenvolvimento para a promoção de ações em saúde e de prevenção dos agravos decorrentes ao ingresso dos indivíduos no presídio. A imunização também faz parte dessas ações, uma vez que o ambiente em questão é propício para o contagio de doenças transmissíveis (como gripe e hepatite B), sendo essa ação cabível as coordenadorias estaduais e ou municipais. Além de promover ações preventivas, a identificação do adoecimento ou agravos devem ser comunicados a equipe de saúde prisional.

O PNSSP (2003) prevê ações e serviço que promovam à saúde da população prisional, tendo por finalidade contribuir para o controle e redução dos agravos frequentes que acometem aos presos. Ainda está previsto na referida lei que cada unidade prisional terá em

\footnotetext{
${ }^{5}$ Patologias referentes à saúde da mulher.
} 
sua estruturação serviços ambulatoriais que se destinem as necessidades de nível básico de média complexidade. Além disso, é função do PNSSP:

organização do sistema de informação de saúde da população penitenciária; III. a implantação de ações de promoção da saúde, em especial no âmbito da alimentação, atividades físicas, condições salubres de confinamento e acesso a atividades laborais; IV. a implementação de medidas de proteção específica, como a vacinação contra hepatites, influenza, tétano; V. a implantação de ações para a prevenção de tuberculose, hanseníase, diabetes, hipertensão, hepatites, DST/AIDS e dos agravos psicossociais decorrentes do confinamento, bem como a distribuição de preservativos e insumos para a redução de danos associados ao uso de drogas (BRASIL, 2003, p. 2).

As previsões feitas com relação às ações preventivas a serem executadas, estão de acordo com as estimativas das doenças que são mais evidentes no contexto prisional, desta forma, se percebe que o Plano Nacional de Saúde no Sistema Penitenciário (2003) busca atender aos adoecimentos mais evidentes na população presidiária.

Além disso, está previsto um plano orçamentário de acordo com as características das unidades prisionais, e também indica a quem se destina a responsabilidade pelo cuidado da saúde dessa população, esses fatores estão condicionados a capacidade populacional que cada casa prisional abriga. De acordo com o PNSSP as características referentes a equipe de saúde prisional, assim como a verba destinada para cada unidade são as seguintes:

Art. $5^{\circ}$ Criar o Incentivo para a Atenção à Saúde no Sistema Penitenciário, cabendo ao Ministério da Saúde financiar o correspondente a $70 \%$ do recurso e ao Ministério da Justiça o correspondente a $30 \%$ do recurso.

$\S 1^{\circ}$ Em unidades prisionais com o número acima de 100 pessoas presas, serão implantadas equipes de saúde, considerando uma equipe para até 500 presos, com incentivo correspondente a R \$ 40.008,00/ano por equipe de saúde implantada.

$\S 2^{\circ}$ Em unidades prisionais com o número de até 100 pessoas presas, as ações e serviços de saúde serão realizadas por profissionais da Secretaria Municipal de Saúde, à qual será repassado Incentivo, no valor de R\$ 20.004,00/ano por estabelecimento prisional.

$\S 3^{\circ}$ Esse incentivo financiará as ações de promoção da saúde e de atenção no nível básico relativos à saúde bucal, saúde da mulher, doenças sexualmente transmissíveis e AIDS, saúde mental, hepatites, tuberculose, hipertensão, diabetes, hanseníase, bem como a assistência farmacêutica básica, imunizações e coleta de exames laboratoriais.

Art. $8^{\circ}$ Estabelecer que a atenção básica de saúde, a ser desenvolvida no âmbito das unidades penitenciárias, será realizada por equipe mínima, integrada por médico, enfermeiro, odontólogo, assistente social, psicólogo, auxiliar de enfermagem e auxiliar de consultório dentário (BRASIL, 2003, p. 2-3).

Os incentivos financeiros estão destinados para ações de promoção em saúde, os serviços, assim como as ações previstas para a atenção básica organizadas nas cadeias, são realizados por equipes interdisciplinares, com o intuito de tratar $100 \%$ da população penitenciária masculina, feminina e psiquiátricas. 
De acordo com a portaria $\mathrm{n}^{\circ} 277$, de 27 de janeiro de 2017 sobre a Política Nacional de Atenção Integral à Saúde das Pessoas Privadas de Liberdade no Sistema Prisional (PNAISP) no âmbito do SUS, em seu Art. $2^{\circ}$ "Os serviços de saúde nos estabelecimentos prisionais serão conformados de acordo com a população prisional e o funcionamento dos serviços, e serão classificados em 3 (três) faixas de acordo com a população prisional" (BRASIL, 2017, p. 1).

\begin{tabular}{|c|c|c|}
\hline Tipo de equipe & Mínimo de membros componentes de cada equipe & $\begin{array}{l}\text { Número de custodiados } \\
\text { por unidade prisional }\end{array}$ \\
\hline $\begin{array}{c}\text { Equipe de Atenção } \\
\text { Básica Prisional } \\
\text { tipo I }\end{array}$ & $\begin{array}{l}1 \text { (um) cirurgião-dentista; } \\
1 \text { (um) enfermeiro; } \\
1 \text { (um) médico; } \\
1 \text { (um) técnico de enfermagem/auxiliar de enfermagem; e } \\
1 \text { (um) técnico de higiene bucal/auxiliar de saúde bucal. }\end{array}$ & Até 100 custodiados \\
\hline $\begin{array}{c}\text { Equipe de Atenção } \\
\text { Básica Prisional } \\
\text { tipo I com Saúde } \\
\text { Mental }\end{array}$ & $\begin{array}{l}1 \text { (um) psiquiatra ou médico com experiência em saúde } \\
\text { mental; } \\
2 \text { (dois) profissionais selecionados dentre as ocupações } \\
\text { abaixo: } \\
\text { a) assistência social; } \\
\text { b) enfermagem; } \\
\text { c) farmácia; } \\
\text { d) fisioterapia; } \\
\text { e) psicologia; ou } \\
\text { f) terapia ocupacional. }\end{array}$ & Até 100 custodiados \\
\hline $\begin{array}{c}\text { Equipe de Atenção } \\
\text { Básica Prisional } \\
\text { tipo II }\end{array}$ & $\begin{array}{l}1 \text { (um) assistente social; } \\
1 \text { (um) cirurgião-dentista; } \\
1 \text { (um) enfermeiro; } \\
1 \text { (um) médico; } \\
1 \text { (um) psicólogo; } \\
1 \text { (um) técnico de enfermagem/auxiliar de enfermagem; } \\
1 \text { (um) técnico de higiene bucal/auxiliar de saúde bucal; e } \\
1 \text { (um) profissional selecionado dentre as ocupações abaixo: } \\
\text { a) assistência social; } \\
\text { b) enfermagem; } \\
\text { c) farmácia; } \\
\text { d) fisioterapia; } \\
\text { e) nutrição; } \\
\text { f) psicologia; ou } \\
\text { g) terapia ocupacional. }\end{array}$ & $\begin{array}{l}\text { De } 101 \text { custodiados até } 500 \\
\text { custodiados }\end{array}$ \\
\hline $\begin{array}{c}\text { Equipe de Atenção } \\
\text { Básica Prisional } \\
\text { tipo II com Saúde } \\
\text { Mental }\end{array}$ & $\begin{array}{l}1 \text { (um) psiquiatra ou médico com experiência em saúde } \\
\text { mental; } \\
2 \text { (dois) profissionais selecionados dentre as ocupações } \\
\text { abaixo: } \\
\text { a) assistência social; } \\
\text { b) enfermagem; } \\
\text { c) farmácia; } \\
\text { d) fisioterapia; } \\
\text { e) psicologia; ou } \\
\text { f) terapia ocupacional. }\end{array}$ & $\begin{array}{l}\text { De } 101 \text { custodiados até } 500 \\
\text { custodiados }\end{array}$ \\
\hline $\begin{array}{c}\text { Equipe de Atenção } \\
\text { Básica Prisional } \\
\text { tipo III }\end{array}$ & $\begin{array}{l}\text { Terá a mesma composição da Equipe de Atenção Básica } \\
\text { Prisional tipo II com Saúde Mental, }\end{array}$ & $\begin{array}{l}\text { De } 501 \text { custodiados até } 1200 \\
\text { custodiados }\end{array}$ \\
\hline
\end{tabular}

Tabela 1: Composição das equipes básicas de saúde prisional e descrição dos tipos de equipe de saúde por unidade prisional e seus respectivos números de custodiados 
Fonte: Política Nacional de Atenção Integral à Saúde das Pessoas Privadas de Liberdade no Sistema PrisionalPNAISP (BRASIL, 2017).

Os serviços de saúde de que trata 0 art. $2^{\circ}$ serão prestados por equipes multiprofissionais, denominadas Equipes de Saúde no Sistema Prisional (ESP), cada equipe será composta de acordo com o número de custodiados de cada estabelecimento prisional. Estando sujeitos a serem acrescidos de mais de uma unidade de saúde quando a população atingir tetos pré-estabelecidos dentro da lei.

Os serviços de saúde que forem prestados dentro das instituições penais devem estar integrados com a Unidades Básica de Saúde (UBS) do Município da qual o presídio está localizado, para que assim sejam desenvolvidas ações integrativas.

\subsection{Saúde prisional da mulher}

As vivências prévias ao encarceramento (baixo acesso a educação, realidade socioeconômica desfavorecida ou até mesmo precária), muitas vezes já são por si só excludentes, inclusive ao que se refere ao acesso à saúde. Não sendo o bastante, o sofrimento se atrela a essa exclusão social e ao acesso de bens culturais e materiais, causando crises na vida dessas pessoas. Com a prisão essas crises se tornam ainda mais severas, pois com o afastamento do convívio social convenciona - fora muros do presídio - torna as mulheres presas restritas a possibilidade que existem dentro do contexto prisional. É notório que as políticas de saúde das mulheres não estabelecem atenção integral e essa ineficácia para suprir suas reais necessidades se agrava ainda mais no contexto prisional.

Por isso, existe a necessidade de se efetivarem as políticas públicas que possuem foco nas mulheres presas. Ressalta-se a importância do atendimento ser realizado por uma equipe comprometida com a saúde prisional feminina. Também é importante que sejam desenvolvidas ações em conjunto com uma equipe composta por diferentes profissionais, para que assim a atenção e cuidado sejam amplos.

De acordo com Regras das Nações Unidas para o tratamento de mulheres presas e medidas não privativas de liberdade para mulheres infratoras -

Regras de Bangkok- (2016, p.21):

A acomodação de mulheres presas deverá conter instalações e materiais exigidos para satisfazer as necessidades de higiene específicas das mulheres, incluindo absorventes higiênicos gratuitos e um suprimento regular de água disponível para cuidados pessoais das mulheres e crianças, em particular mulheres que realizam tarefas na cozinha e mulheres gestantes, lactantes ou durante o período da menstruação. 
O fato das mulheres serem presas gera inúmeros impactos negativos em suas vidas, seja pelo afastamento do convívio familiar, as inúmeras privações, as discriminações. Muitas vezes, elas são abandonadas pelos familiares e com isso seu desamparo é ainda maior. Isso gera prejuízos em sua saúde, tanto mental quanto físicas.

Ainda que o aumento da população prisional feminina seja mais elevado do que da população masculina, o número de presídios destinados para elas ainda é inferior e insuficiente. Com isso, as mulheres que ficam sobre reclusão, muitas vezes, são remanejadas para presídios mistos. Tais locais podem não ter a estrutura física necessária e organizacional para abrigar as pessoas do gênero feminino e todas as suas peculiaridades.

Grande parte dos estabelecimentos que abrigam mulheres, não possuem recursos fundamentais e básicos para atender essa população. A mulher sofre com esse desamparo e adoece, principalmente pelo ciclo de vida feminino exigir atenção de saúde específica.

Como previsto na LEP (1984), os gestores, assim como os profissionais das instituições prisionais devem agir de forma que a atenção disponibilizada por eles para a população que vive em presídios seja enquadrada dentro da política do SUS. Com isso, o sistema de referências e contrarreferência devem ocorrer especialmente em casos de emergência que necessitem de atendimentos especializados. Também devem ocorrer dessa fomra as hospitalizações e procedimentos que se caracterizam como alta complexidade , que de acordo com o Conselho Nacional de Secretários de Saúde - CONASS (2007); "Procedimentos especializados realizados por profissionais médicos, outros profissionais de nível superior e nível médio" (BRASIL, 2007, p. 17).

Em um estudo desenvolvido por Canazaro e Argimon (2010), realizado com 287 mulheres de um presídio no Rio Grande do Sul, demonstrou que existe alta prevalência de sintomatologia grave de depressão. Quase a metade da amostra (48,7\%) que foi investigada apresentou os sintomas. Para eles, o adoecimento psíquico no ambiente prisional tem relação com o tempo de reclusão e situação jurídica relacionados com sintomas depressivos. Porém, as mulheres que trabalham na prisão apresentam menos sintomas depressivos. Entende-se que a atividade laboral de trabalho, nesse ambiente, caracteriza-se como um contribuinte para a diminuição desses sintomas. Todavia, quem estuda na prisão não apresenta diferenças relevantes. Aspectos pessoais, como por exemplo, ser mãe gera influencias negativas que contribuem para que ocorra maior índice de adoecimento psíquico. No estudo desenvolvido por Canazaro e Argimon (2010, p. 5-6):

Ideação suicida, percepção de possuir um problema psicológico, história de tratamento psiquiátrico, tentativa de suicídio, familiares com problemas 
psiquiátricos e história de violência não-sexual aumentam significativamente a probabilidade da ocorrência de sintomatologia grave.

Segundo Moraes e Dalgalarrondo (2006), as pessoas do gênero feminino presas, de maneira geral, antes de serem presas não tinham estabilidade trabalhista, tendo ocupações de baixa qualificação ou estavam desempregadas. A historia de vida dessas pessoas já é marcada muitas vezes pela falta de vínculos familiares saudáveis, falta de acesso a escolarização, além de serem marcadas por variadas formas de violência. Por esses motivos, o aprisionamento das mulheres é marcado por situações precárias de abandono familiar, de estigmatização social e altos níveis de problemas de saúde com ênfase para o sofrimento mental. Garantir os direitos da população como um todo já é algo bastante limitado em todo o país. Quando nos referimos aos direitos das pessoas reclusas em presídios, a situação é ainda mais drástica, principalmente no que se refere à saúde das mulheres.

A Política Nacional de Atenção às Mulheres em Situação de Privação de Liberdade e Egressas do Sistema Prisional - PNAMPE (2014) representa um avanço importante para as políticas de atenção as mulheres no sistema prisional. A PNAMPE visa de reformular as práticas do sistema prisional brasileiro, contribuindo para a garantia dos direitos das mulheres, brasileiras e estrangeiras.

Torna-se relevante destacar que a PNAMPE foi instituída através da Portaria Interministerial $\mathrm{n}^{\mathrm{o}} 210$, de 16 de janeiro de 2014, entre o Ministério da Justiça e a Secretaria de Políticas para as Mulheres da Presidência da República. Todavia, o Ministério da Saúde não faz redação desse texto. $\mathrm{O}$ que por vez indica uma, indicando fragilidade no âmbito intersetorial dessa política. Em suas diretrizes ao que se refere à humanização das condições do cumprimento da pena, prevê a garantia do direito à saúde. Na PNAMPE em seu Art. $3^{\circ}$ que trata dos objetivos da Portaria:

II - induzir para o aperfeiçoamento e humanização do sistema prisional feminino, especialmente no que concerne à arquitetura prisional e execução de atividades e rotinas carcerárias, com atenção às diversidades e capacitação periódica de servidores (BRASIL, 2014, p. 1).

O objetivo da PNAMPE é de garantir a humanização do cumprimento da pena, com vistas ao direito à saúde, educação, alimentação, trabalho, segurança, proteção à maternidade, lazer, esporte, assistência jurídica e demais direitos humanos, fatores estes que têm como alvo melhorar a qualidade de vida e de saúde da população carcerária feminina, priorizando a atenção integral a partir de atividades de prevenção e promoção da saúde. Tendo como metas:

I - criação e reformulação de bancos de dados em âmbito estadual e nacional sobre o sistema prisional, que contemplem: [...] j) dados relativos à incidência de 
hipertensão, diabetes, tuberculose, hanseníase, Doenças Sexualmente Transmissíveis - DST, Síndrome da Imunodeficiência Adquirida - AIDS-HIV e outras doenças; k) quantidade de mulheres inseridas em programas de atenção à saúde mental e dependência química; II - incentivo aos órgãos estaduais de administração prisional para que promovam a efetivação dos direitos fundamentais no âmbito dos estabelecimentos prisionais, levando em conta as peculiaridades relacionadas a gênero, cor ou etnia, orientação sexual, idade, maternidade, nacionalidade, religiosidade e deficiências física e mental, bem como aos filhos inseridos no contexto prisional, $[. .$.$] b) acesso à saúde em consonância com a Política Nacional de$ Atenção Integral à Saúde das Pessoas Privadas de Liberdade no Sistema Prisional, a Política Nacional de Atenção Integral à Saúde da Mulher e as políticas de atenção à saúde da criança, observados os princípios e as diretrizes do Sistema Único de Saúde - SUS, bem como o fomento ao desenvolvimento de ações articuladas com as secretarias estaduais e municipais de saúde, visando o diagnóstico precoce e tratamento adequado, com implantação de núcleos de referência para triagem, avaliação inicial e encaminhamentos terapêuticos, voltados às mulheres com transtorno mental. [...]3. autorização da presença de acompanhante da parturiente, devidamente cadastrada/o junto ao estabelecimento prisional, durante todo o período de trabalho de parto, parto e pós-parto imediato, conforme disposto no art. 19-J da Lei no 8.080, de 19 de setembro de 1990; 4. proibição do uso de algemas ou outros meios de contenção em mulheres em trabalho de parto e parturientes, observada a Resolução no 3, de 1o de junho de 2012, do CNPCP; 5. inserção da gestante na Rede Cegonha, junto ao SUS, [...] 7. respeito ao período mínimo de amamentação e de convivência da mulher com seu filho. [...] III - garantia de estrutura física de unidades prisionais adequada à dignidade da mulher em situação de prisão, de acordo com a Resolução n ${ }^{\circ}$ 9, de 18 de novembro de 2011, do Conselho Nacional de Política Criminal e Penitenciária - CNPCP.

A PNAMPE amplia o olhar sobre a população prisional feminina, pois inclui, dentre de suas ações a prevenção de todos os tipos de violência contra as mulheres presas. Tornando abrangentes os procedimentos e normas de saúde dentro do ambiente prisional.

\subsection{As interfaces da saúde física e saúde mental: uma visão psicossomática}

Partimos da compreensão que tanto corpo quanto mente se inter-relacionam. Logo, exercem influências tanto positivas como negativas, de forma mutua. Compreendemos ainda que algumas pessoas possuem pré-disponibilidade para alguns adoecimentos. Assim como algumas personalidades possuem essa predisposição. Também existem personalidades que possuem mecanismos de defesa que agem de forma protetiva.

Pra Castro, Andrade e Muller (2006, p. 42):

As doenças psicossomáticas questionam a divisão que se faz entre doenças físicas e psíquicas, como se fossem de natureza diferente, decorrendo esta divisão da tradição cartesiana que separa a mente do corpo. É provável que em pouco tempo conceitos que hoje nem conhecemos se tornem verdades, temporárias ou não. Caindo no lugarcomum: não há uma verdade absoluta,ao abordamos a ciência e a arte de lidar com a saúde e doença, a mente e o corpo. Seguimos reduzindo o homem a minúsculas partículas de volta aos genes, para fazermos o caminho inverso, integrando novamente as partes em direção ao ser uno. 
Para Alexander (1989), as doenças são psicossomáticas, pois fatores emocionais influenciam o funcionamento corporal uma vez que fenômenos orgânicos e psicológicos ocorrem paralelamente no mesmo organismo. Tais fatores podem ser agravados pelo contexto em que cada pessoa se encontra. Como já falado anteriormente, o presídio é um espaço de grande propagação de agravos á saúde, assim como causadora de muitos adoecimentos. Explorar o ambiente prisional, dentro da temática de saúde, implica investigar as influencias que corpo e mente exercem mutuamente. Seja para a proteção ou para o adoecimento.

Segundo o que diz o Caderno de Atenção Básica, no 34 de Saúde Mental do Ministério da Saúde ao que se refere às intervenções em saúde mental.

As intervenções em saúde mental devem promover novas possibilidades de modificar e qualificar as condições e modos de vida, orientando-se pela produção de vida e de saúde e não se restringindo à cura de doenças. Isso significa acreditar que a vida pode ter várias formas de ser percebida, experimentada e vivida. Para tanto, é necessário olhar o sujeito em suas múltiplas dimensões, com seus desejos, anseios, valores e escolhas (BRASIL, p. 23, 2013).

As diretrizes de políticas que regem o sistema de saúde mental compreendem o sujeito dentro de uma perspectiva biopsicossocial, visando considerar os aspectos biológicos, psicológicos e sociais de cada sujeito. Por isso, no contexto prisional tais práticas e percepções de saúde também podem ser guiadas por essa diretriz. Logo, o cuidado dos sujeitos se torna global em seus aspectos particulares de vida, além de não haver dissociação entre corpo e mente.

Com a intenção de um entendimento entre a interação do corpo com a mente, a abordagem psicossomática tem grande relevância para o que buscamos investigar. Por sua vez, esse termo pode reportar-se tanto para os aspectos psicológicos de alguns acometimentos, como de doenças orgânicas. Além disso, essa abordagem investiga as relações entre ambos adoecimentos de forma causal, pois as variáveis psicológicas são colocadas em relação com o orgânico, e adicionadas variáveis orgânicas às variáveis psicológicas.

As queixas somáticas inexplicáveis podem ser compreendidas como sofrimento emocional profundo, ou até mesmo de um sofrimento orgânico que venha a causar prejuízos emocionais severos. Tais manifestações representam um adoecimento complexo, que pode ser identificado através de falta de sono, dores no corpo, falta de apetite, irritabilidade, até mesmo prejuízos no comportamento funcional e pessoal, dentre outros sintomas. Esses sintomas assim como os adoecimentos podem ser consequência, ou agravados pela ineficácia do serviço de saúde. Podendo até mesmo o problema se tornar crônico. $\mathrm{O}$ acesso à saúde é direito 
das pessoas presas. Por isso, cuidar da população prisional é também cuidar de toda a saúde pública.

\section{Algumas considerações}

Este trabalho teve como intuito investigar as políticas públicas voltadas à saúde de pessoas presas, com o enfoque especial nas mulheres. Ao analisarmos os documentos, compreendemos como eles são representativos e relevantes para a população que se encontra no contexto prisional, sobre tudo para as mulheres.

De fato, o Brasil, ao longo da história, vem avançando na construção de uma legislação penitenciaria. Principalmente sobre tudo com relação à saúde prisional no âmbito do Sistema Único de Saúde - SUS, que além de ser proporcionar um conjunto complexo de ações, e serviços voltados à saúde, tem por finalidade promover para toda população garantia de acesso à assistência integral à saúde com equidade.

Foi só em 1984, que a Lei de Execução Penal, 7.210, de 11 de junho de 1984, foi sancionada, uma lei para o sistema de execução penal. A Constituição Federal de 1988, que foi criada quatro anos após a LEP, garante o direito à saúde como sendo universal, ampliando o direito ao acesso a saúde para toda a população sem que haja distinção alguma. A Lei N ${ }^{\circ}$ 8.080 de 19 de setembro de 1990, que é Lei Orgânica de Saúde, reforça que a saúde é um direito fundamental do ser humano, devendo o Estado prover as condições indispensáveis ao seu pleno exercício. O Plano Nacional de Saúde no Sistema Penitenciário-PNSSP essencialmente, reduzir as diferenças entre a vida intra e extramuros visando o bem-estar físico e psíquico da população (masculina, feminina e psiquiátrica). A Política Nacional de Atenção Integral à Saúde das Pessoas Privadas de Liberdade no Sistema Prisional- PNAISP, amplia o acesso à saúde às pessoas recolhidas em qualquer estabelecimento prisional, e também àquelas que circulam em espaços prisionais (familiares e trabalhadores).

Embora muitos avanços tenham ocorrido nas últimas décadas ainda existe uma grande lacuna para a efetivação dos direitos à saúde para as pessoas presas. Há escassez de recursos, com isso, a qualidade dos atendimentos fica comprometida. A arquitetura degradada e que não condiz com as especificidades de gênero, bem como a estrutura física inadequada, somam-se a falta ou até mesmo inexistência de profissionais da área da saúde para a efetivação de ações multidisciplinares e interdisciplinares para promoção de uma melhoria da saúde física e mental das pessoas presas. 
Além disso, é necessário que haja capacitação dos servidores do sistema penitenciário com foco na perspectiva de Gênero e Direitos Humanos a fim de diminuir a violência de gênero.

Dessa forma, percebe-se que é evidente que existem contradições entre as políticas, e as práticas de saúde que são executadas dentro do contexto prisional. Contudo, temos o entendimento que é necessário haver o respaldo com a legislação. Para que sejam identificadas incongruências e distanciamentos entre o conteúdo das práticas de saúde, e as leis vigentes.

\section{Referências}

ALEXANDER, F. Medicina Psicossomática. Artes Médicas. Porto Alegre, 1989.

BRASIL. Ministério da Saúde. Plano Nacional de Saúde no Sistema Penitenciário. Brasília, 2004.

. Cadernos de Atenção Básica, n. 34, Brasília: Ministério da Saúde, 2013. Disponível em: http://189.28.128.100/dab/docs/portaldab/publicacoes/caderno_34.pdf Acesso em: 14 mar. 2017.

Lei $\mathrm{N}^{\circ}$ 7.210, de 11 de Julho de 1984. Lei das Execuções Penais-LEP. Disponível em: <http://www.planalto.gov.br/ccivil_03/leis/L7210.htm>. Acesso: 15 maio 2017.

. Lei no 11.942 de 28 de maio de 2009. Altera a lei de Execução Penal. Disponível em: <http://www.planalto.gov.br/ccivil_03/_ato2007-2010/2009/lei/111942.htm>. Acesso em: 24 abr. 2018.

$\begin{array}{lllllll}\text { L Lei } & N^{\circ} & 8.080, & \text { de } 19 & \text { de } & \text { Setembro de } 1990\end{array}$ <http://www.planalto.gov.br/ccivil_03/leis/18080.htm> Acesso em: 29 abr. 2018.

Texto constitucional promulgado em 5 de outubro de 1988, com as alterações determinadas pelas Emendas Constitucionais de Revisão nos 1 a 6/94, pelas Emendas Constitucionais nos 1/92 a 91/2016 e pelo Decreto Legislativo no 186/2008.

- Conselho Nacional de Secretários de Saúde. Assistência de Média e Alta Complexidade no SUS. Brasília : CONASS, 2007.

BRASIL. Conselho Nacional de Justiça. Regras de Bangkok. Brasília, 2016

Conselho Nacional de Justiça. Regras de Mandela: Regras Mínimas das Nações Unidas para o Tratamento de Presos /Conselho Nacional de Justiça, Departamento de Monitoramento e Fiscalização do Sistema Carcerário e do Sistema de Execução de Medidas Socioeducativas, Conselho Nacional de Justiça - 1. Ed - Brasília: Conselho Nacional de Justiça, 2016.

CANAZARO, D.; ARGIMON, I. I. L. Características, sintomas depressivos e fatores associados em mulheres encarceradas no Estado do Rio Grande do Sul, Brasil. Cad. Saúde 
Pública. 2010, v. 26, n.7, p.1323-1333. Disponível em: <http://dx.doi.org/10.1590/S0102311X2010000700011>. Acesso em: 24 abr. 2018

LUDKE, M.; ANDRÉ, M. E. D. A. Pesquisa em educação: abordagens qualitativas. São Paulo: EPU, 1986.

MORAES, P. A. C.; DALGALARRONDO, P. Mulheres encarceradas em São Paulo: saúde mental e religiosidade. J. bras. psiquiatr., Rio de Janeiro, v. 55, n. 1, p. 50-56, 2006. 